\title{
A professora da educação infantil e suas condições de saúde: avaliação do nivel de stress de professoras de um Sistema Municipal de Ensino
}

\author{
Pre-school teachers and their health conditions: evaluation of the \\ stress level of teachers of a Municipal Education System
}

Maria Lúcia Nejm de Carvalho ${ }^{1}$

Fernanda Rossi ${ }^{2}$

\begin{abstract}
Resumo
Objetiva-se analisar a presença de sintomas de stress em professoras da educação infantil de um Sistema Municipal de Ensino de uma cidade do interior de São Paulo, com vistas a identificar as fases do stress e as sintomatologias apresentadas (sintomas: somáticos, psicológicos e ambos) e mapear as fontes geradoras do stress ocupacional. Participaram da pesquisa 42 professoras. Trata-se de estudo descritivo e na coleta de dados utilizou-se um questionário sociodemográfico com questões fechadas referentes à caracterização das participantes e situações relacionadas ao stress ocupacional e o Instrumento de Sintomas de Stress para Adultos (ISSL) para avaliar a presença, o tipo e as fases de sintomas de stress. Os resultados apontaram que 31 professoras apresentaram stress, a maioria na fase de resistência e com prevalência dos sintomas psicológicos. As fontes de stress ocupacional destacadas foram: turmas com muitas crianças, atitudes e comportamentos dessas, atitudes e comportamentos dos pares e dos pais, falta de materiais e de espaço físico, entre outras. Tais resultados evidenciam a necessidade de programas voltados para a saúde do professor.
\end{abstract}

Palavras-chaves: Educação Infantil. Saúde do professor. Estresse.

\footnotetext{
${ }^{1}$ Possui graduação em Formação de Psicólogo e Psicologia pela Universidade do Sagrado Coração (1990) e mestrado em Psicologia (Psicologia Clinica) pela Pontifícia Universidade Católica de São Paulo (2004). Doutorado em Ciências da Reabilitação no Hospital de Reabilitação de Anomalias Craniofaciais da Universidade de São Paulo-HRAC/USP (2012). Tem experiência na área de Psicologia, atuando principalmente nos seguintes temas: cuidado à saúde das pessoas, qualidade de vida, obesidade infantil, aspectos emocionais da amamentação. E-mail: malunejm@yahoo.com.br.

2 Atualmente é Professora Assistente Doutora do Departamento de Educação da Faculdade de Ciências, Unesp Bauru, atuando nos cursos de Licenciatura em Educação Física e Pedagogia, nas áreas de Didática, Estágio Supervisionado, Corporeidade e Movimento e Educação Infantil. Auta no Programa de Pós-Graduação em Docência para a Educação Básica (mestrado profissional) e no PPG acadêmico Ciências da Motricidade. E-mail: fernandarossiunesp@gmail.com.
} 


\begin{abstract}
This study investigates the presence of stress symptoms in pre-school teachers of a Municipal Teaching System of a city in the interior of São Paulo, in order to verify the phases of stress and the symptoms presented (symptoms: somatic, psychological and both) and to map the sources of occupational stress. Fortytwo teachers participated in the study. This was a descriptive study and data collection was performed using a sociodemographic questionnaire with closed questions regarding the characterization of participants and situations related to occupational stress and the Instrument of Stress Symptoms for Adults (ISSL) to assess the presence, type and the phases of stress symptoms. The results showed that 31 teachers presented stress, most in the resistance phase and with prevalence of psychological symptoms. The main sources of occupational stress were: classes with many children, attitudes and behaviors, attitudes and behaviors of peers and parents, lack of materials and physical space, among others. These results evidenced the need for programs focused on teacher health.
\end{abstract}

Keywords: Pre-school education. Teacher health. Stress.

\title{
Introdução
}

Estamos testemunhando, desde o século XX, mudanças complexas e vertiginosas das estruturas sociais, científicas e educacionais (avanços científicos e tecnológicos, emergência da sociedade do conhecimento, globalização, entre outros), nas formas de organização da produção/distribuição e nas estruturas materiais, bem como paradoxos e contradições entre os usos sociais e educativos que implicam em mudanças no papel da escola e na função de professor (IMBERNÓN, 2016).

Neste cenário atual, complexo e incerto, os professores buscam constantemente novas formas de ensino e se deparam, no discurso social e pedagógico dominante, com a prevalência de uma hiper-responsabilização da sua função no sentido de elevar a qualidade do ensino (SACRISTÁN, 1999), configurando um sistema escolar centrado na figura do professor, com uma tendência para que problemas políticos e sociais sejam redefinidos como problemas pedagógicos (NÓVOA, 1999). 
As condições de trabalho, o excesso de cobrança e a desvalorização do professor e da profissão docente podem causar efeitos importantes sobre a sua saúde física e mental, além de afetar o desempenho profissional.

Ao analisar os principais fatores que perpassam o trabalho docente na educação infantil brasileira, Vieira e Oliveira (2013) constataram, com base em revisão bibliográfica (2002-2012), que a realidade profissional dos(as) trabalhadores(as) deste nível de ensino é marcada por situações de stress, mal-estar, adoecimento e insatisfação laboral. Silveira et al. (2014) reafirmam a intensa vulnerabilidade ao stress na docência, ancorados nos resultados apresentados em estudo de revisão de literatura em bases internacionais de artigos publicados entre 2006 e 2011 sobre as relações entre stress e coping em professores.

O stress ocupacional, reconhecido por organismos internacionais como enfermidade profissional (MARTINS, 2007), refere-se ao stress causado pelo trabalho e pode ser compreendido como a interação de características do indivíduo e as condições laborais (GOMES; PEREIRA, 2008); sendo que as demandas profissionais apresentadas tendem a ultrapassar a capacidade de enfrentamento do indivíduo (FRANÇA; RODRIGUES, 2002). Pode-se dizer que há um processo de desequilibrio entre as demandas profissionais e as respostas a elas dadas pelo indivíduo (ROSI, 2003; MELEIRO, 2008).

Estudos sistemáticos apontam que no Brasil mais da metade dos docentes apresentam manifestações de stress (LIPP, 2002; REINHOLD, 2004; MARTINS, 2007); no entanto, poucos são os estudos que se ocupam do segmento da educação infantil (ROSI, 2003). Ainda, tendo em vista os custos emocionais do stress e o seu impacto no desenvolvimento da função profissional, reconhecemos a necessidade de novas investigações junto a essa população.

Nesta pesquisa, o objetivo consistiu em analisar a presença de sintomas de stress em professoras da educação infantil de um Sistema Municipal de Ensino de uma cidade do interior de São Paulo. Os objetivos específicos consistiram em identificar as fases do stress em que as professoras se 
encontravam, as sintomatologias apresentadas (sintomas: somáticos, psicológicos e ambos) e mapear as fontes geradoras do stress ocupacional.

\section{Da docência e do stress}

As diversas demandas dos professores da educação infantil, que perpassam pelo educar e cuidar, podem gerar a intensificação do trabalho docente e tornar sua atividade diária estressante. Por lidar com um elevado número de crianças que procedem de famílias com diferentes configurações de educação dos filhos, ressalta Meleiro (2008), os professores relacionam-se com pais que podem ser excessivamente tolerantes não colocando regras e limites em seus filhos que encontram dificuldades ao se depararem com o novo mundo que se descortina no ambiente escolar e no convívio de outras crianças.

O mesmo autor pontua que na educação infantil é comum a ocorrência de pequenos traumatismos por queda ou agressão de outra criança, bem como a ocorrência de doenças transmissiveis. Alguns pais acabam levando a criança doente para a escola, sem comunicarem a direção, por não terem onde deixála. Além disso, com certa frequência, alguns deles reclamam do professor, por julgarem que o mesmo não cuida adequadamente de seus filhos.

Ampliando o foco para além da educação infantil constata-se que as fontes de stress na docência, sobretudo nas séries iniciais do ensino fundamental, podem ser diversas, tais como: lidar com incidentes advindos de comportamentos desafiadores dos alunos (KELLY et al., 2007); diferenças de desenvolvimento e motivação, comportamentos inadequados e indisciplina dos alunos; trabalho excessivo e consequente falta de tempo livre e a maneira como são planejadas, definidas e implementadas as políticas educacionais (POCINHO; CAPELO, 2009).

Ainda, considerando a docência como um todo, podem ser acrescidos os seguintes fatores: cobranças da sociedade, das escolas e dos pais; circunstâncias desfavoráveis como prédios mal cuidados, falta de materiais

didáticos, falta de segurança nas escolas, autoexigência do docente para 
manter-se atualizado para lidar com as expectativas e necessidades dos alunos (MARTINS, 2007), a forma e a intensidade como ocorrem as relações interpessoais entre professores, gestores, alunos, funcionários e demais envolvidos no cotidiano escolar (BOA MORTE; DEPS, 2015).

Cabe destacar que tanto as professoras como os professores precisam lidar com a carga emocional e social advindas das tensões e desafios que permeiam suas vidas pessoais e profissionais; já que além da responsabilidade profissional muitos deles podem assumir para si a responsabilidade e a manutenção da sua vida familiar, ocorrendo a dupla jornada de trabalho, sobretudo, no caso das mulheres (VIANNA, 2001/2002).

Sob a ótica dos estudos de gênero, Zibetti e Pereira (2010) ao analisar as condições de vida e trabalho de mulheres que atuam na docência em educação infantil e nas séries iniciais do ensino fundamental de redes municipais do interior do estado de Rondônia, concluíram a existência de tensões geradas pela desigual divisão das atribuições domésticas entre mulheres e homens, sendo comum as jornadas duplas, de trabalho doméstico e trabalho docente, ou até mesmo jornadas mais extensas (com atividades de planejamento fora do horário de trabalho, por exemplo), intensificando os processos de trabalho e repercutindo de forma negativa sobre a qualidade de vida e do trabalho docente das mulheres-professoras.

Conforme Vieira e Oliveira (2013), no Censo Escolar de 2012 realizado pelo Instituto Nacional de Estudos e Pesquisas Educacionais/INEP, vinculado ao Ministério da Educação/MEC, as mulheres compunham um universo de $97 \%$ dos 443.405 docentes da educação infantil. Cinco anos depois, o número de docentes nesta etapa da educação básica aumentou, com pouca alteração na proporção do número de mulheres, já que os dados do Censo de 2017 apontam que na educação infantil brasileira atuam hoje 557,5 mil professores. Desse total, 49,1\% atuam em creches e $57,5 \%$ atuam em préescolas, sendo que $96,6 \%$ que atuam na educação infantil são do sexo feminino (BRASIL, 2017).

Ao tratar do stress, Bauk (1985) elucida que esse termo advém da área da Engenharia e da Física, com base em testes aplicados para a verificação de 
quanto um material poderia suportar de força nele direcionada antes de ocorrer o seu rompimento.

Com semelhanças próximas às ideias de Bauk, um endocrinologista Selye (1959) introduziu em 1936, a terminologia na área da saúde, fazendo referências às reações elaboradas pelo sistema biológico como forma de resposta frente às situações nocivas ao organismo. Desde então, estudos foram sendo desenvolvidos de maneira que o conceito foi se tornando mais abrangente.

Em vista disso, Lazarus e Folkman (1984) destacaram que o stress transpassava a esfera biológica, sendo relevante a atuação da área cognitiva no momento de resposta aos diferentes estímulos. Em outro estudo (1986), os autores corroboraram a ampliação do conceito de stress como um processo interativo.

Gonzáles Rey (1997) destacou que Lazarus descortinou um novo entendimento do stress, transcendendo a visão do mesmo em termos de estímulo e resposta para uma perspectiva interativa da sua essência e da sua etiologia; perspectiva essa que considera relevantes as relações do homem com o seu entorno. Por fim, afirmou que a ênfase dada por Lazarus ao stress como um processo, representou um avanço para o desenvolvimento do tema saúde em uma visão pluridimensional.

Vasconcelos (1992), seguindo um prisma além do biológico e cognitivo, pontuou o stress como um fenômeno biopsicossocial que poderia ocorrer diante de estímulos biológicos, psicológicos e sociais.

Lipp (1984), ampliando um pouco mais, abordou o stress como uma reação psicológica, com componentes físicos, emocionais, químicos e mentais, frente a estímulos estranhos ou estressores que poderiam amedrontar, irritar, excitar ou confundir a pessoa.

A mesma autora em outro estudo (LIPP, 2005) reafirmando ser o stress emocional uma reação global e complexa do organismo, envolvendo aspectos físicos, psicológicos, mentais e hormonais, que se desenvolve diante da necessidade de uma adaptação a uma situação ou evento importante, chama a atenção para o fato de que esse evento pode ter sentidos negativos ou 
positivos. Sendo assim, o stress positivo pode ser entendido como aquele que se manifesta em uma fase inicial - a do alerta. A pessoa tendo em vista a produção de adrenalina que propicia vigor e energia pode produzir mais e ser mais criativa. Vale lembrar que essa fase de alerta não pode durar demais, pois o stress pode se tornar excessivo, passando a ser negativo. Em seu sentido negativo pode levar a pessoa a ter a sua produtividade e capacidade de trabalho prejudicada, ou ao adoecimento quando ultrapassa os seus limites e esgota a sua capacidade de adaptação. E finalmente em sua ótica ideal, pode ser bem administrado, apresentando um equilíbrio no gerenciamento da fase do alerta, alternando o estar em alerta com o sair de alerta; permitindo que o organismo tenha um período de recuperação antes de iniciar uma nova fase de alerta.

O percurso do stress pode ser estudado com base no modelo quadrifásico (LIPP, 2005), que contempla as fases do Alerta, da Resistência, de Quase-Exaustão e de Exaustão.

Fase do Alerta: entendida como a fase positiva do stress, em que o ser humano, com a produção e ação da adrenalina, fica mais forte, motivado e atento. Pode, frequentemente, alcançar a sensação de plenitude.

Fase da Resistência: é aquela na qual o ser humano busca administrar os seus estressores de forma a manter a sua homeostase interna, ou seja, equilíbrio interior. Caracteriza-se pela produção de cortisol e maior vulnerabilidade a virus e bactérias.

Fase de Quase-Exaustão: pode ser vista como aquela na qual o ser humano vivencia uma gangorra emocional, sendo que com esforços consegue intercalar momentos de funcionamento normal com os de total desconforto. Em geral há muita ansiedade e maior produção de cortisol. As defesas imunológicas começam a ser destruídas e consequentemente vão surgindo as doenças.

Fase de Exaustão: compreendida como a fase mais negativa do stress a patológica. Predomina um desequilíbrio interno muito grande, sendo que a pessoa, entrando em depressão, não consegue se concentrar ou trabalhar. Doenças graves, como pressão alta, úlcera, psoríase e vitiligo podem vir a 
ocorrer (LIPP, 2005). Cabe destacar que o modelo quadrifásico do stress constitui como base para a elaboração do Inventário de Sintomas de Stress de Lipp (ISSL).

Considerando o elevando número de docentes brasileiros - mais da metade - que apresentam manifestações de stress (LIPP, 2002; REINHOLD, 2004; MARTINS, 2007), a vulnerabilidade e propensão ao stress dessa classe profissional (ANDRADE; CARDOSO, 2012) e o impacto e os efeitos que este quadro pode causar aos professores, sobressai a necessidade de investir em estudos e pesquisas para identificar a ocorrência de stress no âmbito da profissão docente, bem como refletir sobre ações que possam evitar ou amenizar os sintomas do stress em busca de melhor qualidade de vida na docência.

\section{Metodologia}

Esta pesquisa consiste em um estudo descritivo, com análises qualiquantitativas, considerando como Chizzotti (1998, p. 34) que a pesquisa quantitativa e a qualitativa "devem sinergicamente convergir na complementaridade mútua". Participaram do estudo 42 professoras da educação infantil de um Sistema Municipal de Ensino de uma cidade do interior de São Paulo, abrangendo 36 escolas, que se inscreveram em um Projeto de Extensão desenvolvido por uma Universidade pública, cujo objetivo consistiu em desenvolver ações de formação continuada com vivências e estudos teóricos relacionados à manifestação corporal yoga, com o foco no desenvolvimento pessoal e profissional docente.

O estudo foi aprovado pelo Comitê de Ética em Pesquisa da referida Universidade ${ }^{3}$.

A coleta de informações ocorreu por meio de um questionário sociodemográfico contendo questões fechadas abordando os seguintes itens: idade, estado civil, formação acadêmica, tempo de exercício profissional,

\footnotetext{
${ }^{3}$ A identificação da Universidade sede do Comitê de Ética e o número do parecer foram suprimidos nesta versão do manuscrito em função do critério de "avaliação cega por pares".
} 
jornada de trabalho, quantidade de alunos na turma e fatores geradores de stress na rotina de trabalho. A coleta foi realizada em um laboratório ludopedagógico da Universidade, espaço adequado para a coleta de informações por possibilitar a preservação do sigilo.

Além do questionário sociodemográfico, também foi utilizado um teste psicológico: Inventário de Sintomas de Stress para Adultos de Lipp (ISSL), padronizado e validado para a população brasileira (LIPP, 2005) com o objetivo identificar a sintomatologia do sujeito, avaliando a presença de sintomas de stress, o tipo de sintomas prevalentes (psicológico ou somático) e as fases do stress: Alerta, Resistência, Quase-Exaustão e Exaustão. O Inventário é composto de três quadros, referentes às quatro fases do stress, divididos de forma temporal respectivamente nos seguintes ritmos: 24 horas, uma semana e um mês. O primeiro quadro (Q1) avalia a fase 1 (Alerta) englobando um total de 15 sintomas: 12 físicos e 3 psicológicos. O segundo quadro (Q2) avalia as fases: 2 (Resistência) e 3 (Quase-Exaustão), sendo composto de um total de 15 sintomas: 10 físicos e 5 psicológicos. O quadro três (Q3) avalia a fase 4 (Exaustão) com um total de 23 sintomas: 12 físicos e 11 psicológicos. No total, o ISSL perfaz 37 itens de caráter somático e 19 de natureza psicológica. Alguns dos sintomas podem ser repetidos nos diferentes quadros, diferindo nesses casos em grau de intensidade e gravidade. Os resultados são confrontados com as tabelas de avaliação que indicam a presença ou ausência, a fase e a sintomatologia, do stress.

Considerou-se oportuno neste estudo a escolha pelo modelo teórico proposto por Lipp $(1984,2005)$ tendo como parâmetro, principalmente, quatro justificativas: 1- a sua produção científica respeitada nas áreas da Psicologia e da Educação, 2- conceito de stress abrangente, 3- as pesquisas brasileiras, sobre stress, desenvolvidas em diferentes regiões do Brasil, que fizeram uso sistemático do Inventário de Sintomas de Stress de Lipp (ISSL), validado, padronizado para o Brasil e traduzido para o inglês e espanhol e 4- a utilização do ISSL na coleta de dados do presente estudo.

Os instrumentos foram aplicados pela pesquisadora em três grupos, com no máximo 16 pessoas, com o intuito de esclarecer possíveis dúvidas, 
sendo o tempo médio de aplicação do questionário sociodemográfico de quinze minutos e do Instrumento de Sintomas de Stress de vinte minutos.

Os dados do questionário sociodemográfico foram transcritos em tabelas para sua melhor visualização e analisados por meio do estudo das percentagens referentes às variáveis envolvidas na pesquisa. Já os dados obtidos no Instrumento de Sintomas de Stress de Lipp - ISSL foram, primeiramente, corrigidos e avaliados de acordo com as instruções para a apuração dos resultados e, depois, interpretados com base no manual do referido instrumento.

Os resultados são apresentados na sequência e discutidos com fundamentação na literatura relacionada à temática do stress na docência, sobretudo na educação infantil.

\section{Professoras da educação infantil: sintomas, fases e fontes geradoras do stress ocupacional}

Dentre as participantes da pesquisa, 100\% são do gênero feminino, com idades variando de 20 a mais de 60 anos; sendo que 17 estavam na faixa de 41 até 50 anos e 13 na de 31 a 40 anos. No que se refere à formação acadêmica, 27 possuíam especialização, uma mestrado e duas não responderam. Considerando o estado civil, foi constatado que 23 são casadas, 12 solteiras, cinco divorciadas e duas não responderam, conforme apresentado na tabela 1 .

Tabela 1 - Distribuição das frequências das variáveis sociodemográficas e ocupacionais das 42 professoras

Variáveis
Frequência

(n)

\section{Idade}

$20-30$

$31-40$
6

13 
41- 50

17

$51-60$

4

Mais de 60

2

Formação acadêmica

Graduação

12

Especialização

27

Mestrado

Não indicado

2

Estado Civil

Casada

Solteira

Divorciada

Não indicado

Tempo de exercicio

profissional

$1-15$

$16-30$

Mais de 30

Não indicado

Jornada de Trabalho

Parcial

Integral

Não indicado

Quantidade de alunos
$16-20$
$21-25$
13
$26-30$ 
Mais de 30

Não indicado

\section{2}

5

Fonte: autoria própria.

Cabe aqui retomar um dado importante em que se constata que todas as participantes do presente estudo são mulheres, reafirmando os achados de estudos anteriores nos quais os docentes que atuavam na educação infantil eram predominantemente do gênero feminino (VIEIRA; OLIVEIRA, 2013; BRASIL, 2017).

Tendo em vista as variáveis ocupacionais observou-se que 18 professoras encontravam-se na faixa de um até 15 anos de exercício profissional; 16 na faixa de 16 até 30 anos, três com mais de 30 anos e cinco não responderam. Sob a luz da variável jornada de trabalho 19 trabalhavam em jornada parcial, 17 integral e seis não informaram. A quantidade de alunos por turma variou de 16 até 32 crianças.

No Inventário de Sintomas de Stress, constatou-se que o diagnóstico de stress ocorreu em 31 professoras, do total de 42 participantes do estudo. Tal achado vai ao encontro de resultados de estudos anteriores (ROSI, 2003; REINHOLD, 2004; MARTINS, 2007) sendo que em todos eles mais da metade dos participantes apresentaram manifestações sintomáticas de stress. Corroboram esses dados Gasparini, Barreto e Assunção (2005), ao relatarem que os transtornos psíquicos foram identificados em primeiro lugar entre os diagnósticos de professores em condição de afastamento, na capital de Minas Gerais.

Como nos mostra Lipp (2000) a sintomatologia pode dar indícios da vulnerabilidade da pessoa ao stress; ou seja, se os seus sintomas mais relevantes são físicos, psicológicos ou mistos; direcionando assim as maneiras de administrar ou eliminá-los. Os sintomas psicológicos predominaram em 23 professoras, enquanto que os físicos em cinco e ambos (físicos e psicológicos) somente em três. Esse resultado chama a atenção para a importância dos professores serem compreendidos em seus aspectos físicos e psicológicos. Como destaca Gatti (2003, p. 196): 
É preciso ver os professores não como seres abstratos, ou essencialmente intelectuais, mas, como seres essencialmente sociais, com suas identidades pessoais e profissionais, imersos numa vida grupal na qual partilham uma cultura, derivando seus conhecimentos, valores e atitudes dessas relações, com base nas representações constituídas nesse processo que é, ao mesmo tempo, social e intersubjetivo.

Nesse sentido, cabe considerar, também, a importância de compreender a carga emocional e social decorrentes dos desafios e tensões que permeiam suas vidas pessoais e profissionais (VIANNA, 2001, 2002).

No que se refere às fases do stress, de acordo com o Inventário de Sintomas de Stress, do total de 31 professoras diagnosticadas, a maioria (20) estava na fase de resistência, nove na fase de quase-exaustão e duas estavam na fase de alerta, de acordo com os dados apresentados na tabela 2.

A predominância da fase de resistência foi outro resultado que coaduna com os mesmos estudos acima identificados (ROSI, 2003; REINHOLD, 2004; MARTINS, 2007).

Os sintomas fisicos mais significativos, assinalados pelas professoras que se encontravam na fase de resistência, foram: problemas com a memória (18), sensação de desgaste físico constante (17), cansaço constante (14), insônia (13), mal estar generalizado, sem causa específica e tontura/sensação de estar flutuando (9), excesso de gases (8), dificuldades sexuais (7), mudança extrema de apetite (5) e tontura frequente (3). Com fins de comparação com o estudo de Martins (2007), em relação à sintomatologia da dimensão física, a autora identificou como sintomas mais presentes entre as participantes de seu estudo o cansaço constante, a sensação de desgaste físico constante e problemas com a memória.

\section{Tabela 2 - Sintomas físicos e psicológicos mais significativos nas 31 professoras que apresentaram sintomas de stress}

$\begin{array}{ccccc}\text { Variável } & \text { Total } & \text { Fase } & \text { Fase de } & \text { Fase de } \\ & (31) & & \text { Quase } & \text { Alerta }\end{array}$

(2) 


$\begin{array}{cc}\text { de } & \text { Exaustão } \\ \text { Resistência } & (9) \\ \text { (20) } & \end{array}$

SINTOMAS FÍsICOS

Problemas com a memoria

Sensação de desgaste físico

constante

Cansaço constante

Insônia

Mal estar generalizado s/ causa especifica

Excesso de gases

Dificuldades sexuais

Mudanças extremas de apetite

Mudanças de apetite

Tontura frequente

Problemas dermatológicos

\section{SINTOMAS PSICOLÓGICOS}

Angustia - Ansiedade

Cansaço Excessivo

Sensibilidade emotiva

Pensar constantemente em um

só assunto

Irritabilidade excessiva

Vontade de fugir de tudo

Duvido quanto a si próprio

Diminuição da libido

Hipersensibilidade emotiva

Sensação de incompetência

Fonte: autoria própria

$\begin{array}{llll}90 \% & 90 \% & 100 \% & 50 \% \\ 87 \% & 85 \% & 89 \% & 100 \%\end{array}$

$81 \% \quad 70 \% \quad 100 \% \quad 100 \%$

$65 \% \quad 65 \% \quad 78 \%$

$58 \% \quad 45 \%$

$89 \%$

$50 \%$

$\begin{array}{llll}45 \% & 40 \% & 56 \% & 50 \% \\ 42 \% & 35 \% & 67 \% & \\ 32 \% & 25 \% & 56 \% & \\ 26 \% & & 89 \% & \\ 26 \% & 15 \% & 56 \% & \\ 6 \% & & & 100 \%\end{array}$

$\begin{array}{llll}84 \% & 80 \% & 100 \% & 50 \% \\ 77 \% & 75 \% & 89 \% & 50 \% \\ 71 \% & 65 \% & 100 \% & \\ 71 \% & 65 \% & 78 \% & 100 \% \\ & & & \\ 68 \% & 65 \% & 89 \% & \\ 68 \% & 60 \% & 89 \% & 50 \% \\ 58 \% & 50 \% & 89 \% & \\ 55 \% & 45 \% & 89 \% & \\ 29 \% & & 89 \% & 50 \% \\ 23 \% & & 78 \% & \end{array}$


Ainda em relação à fase de resistência, na categoria dos sintomas psicológicos foram destacados como os mais marcantes pelas professoras: angústia/ansiedade (16); cansaço excessivo (15), sensibilidade emotiva (13), pensar constantemente em um só assunto (13), irritabilidade excessiva (13), vontade de fugir de tudo (12), dúvida quanto a si própria (10) e diminuição da libido (9).

A sintomatologia predominante nos achados de Martins (2007) foram os sintomas psicológicos, sendo os mais significativos: a irritabilidade excessiva, pensar constantemente em um só assunto e sensibilidade emotiva excessiva.

Como apontado pela literatura, a pessoa na fase de resistência está buscando manter a sua homeostase interna, lutando, assim, com os estressores. Além dos desgastes psicológicos, pode estar suscetível a vírus e bactérias, já que o organismo começa a ficar debilitado para atender as demandas advindas dos contextos aos quais faz parte (LIPP, 2000). Evidentemente que ao buscar vencer os sintomas físicos e psicológicos o professor poderá ter mudanças na sua qualidade de vida e no seu desempenho profissional.

Cabe considerar ainda que se os estressores presentes nessa fase persistem em intensidade e frequência pode ocorrer uma quebra da resistência e, consequentemente, uma passagem para a fase de quaseexaustão.

No presente estudo, nove professoras já se encontravam na fase de quase-exaustão sendo que todas apresentavam problemas com a memória, cansaço constante, sensibilidade emotiva e angústia ou ansiedade. Essas sintomatologias associadas com outros sintomas tais como: mal estar generalizado, sensação de desgaste físico constante, mudança de apetite, dúvida quanto a si própria, irritabilidade excessiva, diminuição da libido, vontade de fugir de tudo, hipersensibilidade emotiva e outros, indicam o aumento da produção do cortisol em seus organismos, a diminuição das defesas imunológicas abrindo as portas para a instalação de doenças físicas e emocionais, que poderão, em algumas situações, conduzir à necessidade de 
se ausentarem do ambiente escolar e, consequentemente, aumentarem o indice de absenteísmo.

$\mathrm{Na}$ fase de quase-exaustão a pessoa vive uma gangorra emocional na qual em alguns momentos pode se sentir bem e em outros experimentar um total desconforto; sendo que para retomar o bem estar é preciso muito esforço de sua parte (LIPP, 2000), sobretudo ao tratar da categoria docente, pois no entendimento de Gasparini, Barreto e Assunção (2005, p. 197), “os professores têm mais risco de sofrimento psíquico de diferenciados matizes e a prevalência de transtornos psíquicos menores é maior entre eles, quando comparados a outros grupos".

Em relação às fontes geradoras de stress no trabalho, a tabela 3 indica a distribuição da frequência de respostas: formação de turmas com muitas crianças (33), atitudes e comportamentos das crianças (27), atitudes e comportamento dos pares (27), falta de materiais (23), falta de espaço físico (18), atitudes dos pais (18), cobrança dos superiores (18), jornada de trabalho (13), formação de turmas mistas (2), aposentadoria (1).

\section{Tabela 3 - Distribuição das frequências das fontes de stress apontadas pelas 42 professoras}

Variável

Turmas com muitas crianças

Atitudes e comportamentos

das crianças

Atitudes e comportamentos

dos pares

Falta de materiais

Falta de espaço físico

Atitude dos pais

Cobrança dos superiores

Jornada de trabalho

\section{Frequência}

(n)

33

27

27

23

18

18

18

13 


\section{Turmas mistas}

Aposentadoria

\section{2}

1

Fonte: autoria própria.

Os resultados mostram que das 42 professoras, 33 apontaram como fontes de stress a formação de turmas com muitas crianças; sendo que 24 destas se encontravam com stress nas respectivas fases: resistência (18), quase-exaustão (4) e alerta (2).

Assunção e Oliveira (2009) enfatizam que dentre os impactos causados pelas mudanças nas políticas educacionais das últimas décadas, está a expansão da escolaridade sem que condições objetivas de atendimento fossem instauradas, de modo que esta situação tem resultado em intensificação do trabalho docente, sendo que:

A intensificação do trabalho supõe fazer a mesma coisa mais rapidamente. Contudo, o processo de intensificação provoca a degradação do trabalho não só em termos de qualidade da atividade, mas também da qualidade do bem ou do serviço produzido. Confrontados com a falta de tempo, os trabalhadores limitam a atividade em suas dimensões centrais, que seriam manter o controle da turma e responder aos dispositivos regulatórios. Vale ressaltar que o sofrimento no trabalho, associado ao adoecimento em estudos específicos, está sempre ligado a um conflito entre a vontade de bem fazer o seu trabalho, de acordo com as novas regras implícitas da profissão, e a pressão que os leva a certas regras para aumentar a sua produtividade. (ASSUNÇÃO; OLIVEIRA, 2009, p. 366)

Os resultados encontrados reforçam os apontamentos de Meleiro (2008) no que diz respeito à formação de turmas com muitas crianças que podem apresentar dificuldades de comportamentos e atitudes decorrentes de uma educação em suas casas sem limites claros e bem definidos. Acrescidas a tais dificuldades, muitas vezes ocorrem atitudes de desconfiança dos pais de que o professor possa cuidar de seus filhos da mesma maneira que esses o fazem.

Imbernón (2016) ao ressaltar que a sociedade torna-se cada vez mais complexa, reflete, também, sobre o exercício da função de professor nos tempos atuais como uma tarefa trabalhosa e de uma complexidade crescente, 
emergindo, por vezes, o sentimento de perplexidade entre os docentes pela falta de correspondência entre a educação escolar e aquela recebida na família ou meio circundante. Andrade e Cardoso (2012) ressaltam que as transformações no meio educacional propiciaram que a classe docente se tornasse mais propensa e vulnerável ao stress, sobretudo na educação infantil; na medida em que as famílias se tornaram mais ausentes no processo educacional das crianças.

As atitudes e comportamentos das crianças, assim como as atitudes e comportamentos dos pares, foram indicados pelas professoras participantes do estudo como fatores gerados de stress, com 27 ocorrências para cada um deles. No que se refere às atitudes e comportamentos das crianças pontua-se as diferenças de desenvolvimento e de interesses que apresentam, assim como a maneira como se relacionam com os colegas e professores, podendo tal relacionamento caracterizar-se, algumas vezes, por meio de comportamentos desafiadores e indisciplina (KELLY et al., 2007; POCINHO; CAPELO, 2009).

O fator atitudes e comportamentos dos pares, enfatizado por professoras independentemente de indicarem ou não sintomas de stress, apresenta resultado consonante com o estudo de Boa Morte e Deps (2015) que assinalam que a maneira e a intensidade como são estabelecidas as relações interpessoais entre gestores, professores e demais funcionários podem influenciar não somente no nível de stress, como também na motivação do docente, o qual pode em determinadas situações sentir a falta do reconhecimento pelo seu trabalho.

A falta de reconhecimento ou a desvalorização social da atividade profissional da dupla função de cuidar e educar crianças pequenas em instituições educacionais foi identificada, por Vieira e Oliveira (2013), com um eixo que perpassa o conjunto de estudos científicos sobre o trabalho docente, analisados pelas autoras.

Foram destacadas pelas participantes, ainda, circunstâncias desfavoráveis para o exercício da profissão como falta de materiais e de espaço físico que já haviam sido relatadas por Martins (2007) e Vieira e Oliveira (2013). 
A precarização e a intensificação do trabalho docente são dois processos presentes às condições de trabalho dos professores, identificados em todos os estudos analisados por Vieira e Oliveira (2013, p. 148):

Em sintese, o primeiro [precarização] se refere à atribuição de novas funções e tarefas ao mesmo tempo em que não são fornecidas as condições necessárias para o seu cumprimento. Pode também ser entendido como o emprego de pessoas sem a formação requerida pela legislação educacional, ocupando postos de trabalho criados para substituir professore/as no exercício do trabalho pedagógico. Já o segundo [intensificação] trata da imposição de sobrecarga, seja através da necessidade de realização de atividades extras fora da jornada oficial de trabalho ou mesmo através da baixa remuneração, que exige a complementação salarial por meio do compromisso com outros cargos.

Os resultados encontrados neste estudo permitem refletir sobre os impactos do stress na saúde e na qualidade de vidas dessas professoras; indicando mais uma vez a relevância de trabalhos direcionados à prevenção e intervenção do stress no âmbito da profissão docente. Há que se considerar a necessidade de ações no sentido de evitar que o stress entre em um processo de agravamento de forma que as professoras migrem para fases mais adiantadas. Estas ações perpassam por politicas públicas que valorizem a docência e o profissional da educação, investimentos em condições adequadas de trabalho, atenção à saúde do professor, entre outras iniciativas, dentre as quais se inclui a formação continuada com ações focadas no professor (direcionar o foco para a pessoa (o Ser) e não apenas ao papel profissional). Há uma lacuna a ser preenchida na medida em que projetos no âmbito educativo, sobretudo aqueles desenvolvidos pelos sistemas de ensino, centram-se em modelos de ensino e aprendizagem nos quais o docente não é visto em sua totalidade, desconsiderando que sentir, pensar e agir formam uma tríade fundamental no processo educacional (ROSSI, 2017).

Uma formação docente diferenciada no sentido da integralidade pode contribuir para o desenvolvimento biopsicossocial dos professores, minorando os sintomas do stress e com o propósito de promover a apropriação crítica e criativa de conhecimentos, a adoção de novas práticas/habitus ativos pelos 
participantes, bem como a construção de outros saberes, concepções e formas de atuação, com vista a mudanças em seu estilo de vida, implicando, também, nas interações destes com os diferentes atores educacionais e familiares (alunos, pares, famílias, comunidade, gestores etc.).

Rossi (2013) constata que a formação docente se configura como um elemento multidimensional que não esgota nas questões acadêmicocientíficas e pedagógicas, mas incide também nas dimensões atitudinais e emocionais. Assim, como destacam Nóvoa (2000) e Imbernón (2009), diferentes concepções e práticas de formação precisam ser valorizadas, pois professor (vida profissional) e pessoa (vida pessoal) não se separam.

Dentro de um enfoque sistêmico, o indivíduo (professor) configura-se como um sistema vivo e em movimento, através do tempo (NEDER, 1997), e não existe isolado, pertence e está inserido em outros sistemas (SOUZA, 1997). Portanto, conforme ressalta Imbernón (2009) é preciso investir em ações coletivas e colaborativas entre as instituições (Universidade e Escolas), estabelecendo relações de parcerias e cooperação entre todos os sujeitos envolvidos, viabilizando processos de intervenção que correspondam de forma mais adequada ao momento histórico vivido em um determinado contexto e as necessidades do grupo.

Com esse indicativo pode-se ampliar a compreensão em torno do stress profissional na docência, considerando a interação das atividades profissionais com os acontecimentos das vidas pessoais. Como mencionado por Lipp (2000) são os recursos internos de cada pessoa que irão determinar a sua própria adaptação à realidade.

\section{Considerações finais}

Os resultados desta pesquisa que objetivou analisar a presença de sintomas de stress em professoras da educação infantil de um Sistema Municipal de Ensino paulista vão ao encontro de outros estudos, corroborando que o stress ocupa um lugar significativo na profissão docente.

Constatou-se que o diagnóstico de stress acomete a maioria das professoras investigadas, sendo que este ocorreu em 31 professoras, sendo 42 
o número de participantes do estudo. Dentre as professoras diagnosticadas com sintomas de stress, a maioria estava na fase de resistência, a segunda fase do modelo quadrifásico de Lipp (2005), apresentando como sintomas mais recorrentes problemas com a memória, sensação de desgaste físico frequente, cansaço constante, insônia, angústia/ansiedade, sensibilidade emotiva e irritabilidade excessiva, dente outros.

A fase de resistência caracteriza-se pela busca da administração dos estressores, o que indica que, de alguma maneira, essas professoras estão buscando resistir às fontes de stress para manter o equilíbrio e, assim, não progredir para as fases de exaustão, nas quais algumas docentes já se encontram.

Ao analisar as fontes geradoras de stress desse grupo de professoras da educação infantil, pode-se ressaltar como especificidades da experiência com o stress neste nível de ensino: formação de turmas com muitas crianças, atitudes e comportamentos dos pares e das crianças, falta de materiais e de espaço físico, atitudes dos pais, cobrança dos superiores, jornada de trabalho excessiva, dentre outras com menor incidência.

A educação infantil é o espaço e tempo em que as crianças vivenciam, pela primeira vez, uma socialização intensa com outros adultos e crianças que não são do seu convívio familiar, sendo a professora deste nível de ensino responsável pela adaptação da criança a este novo cenário social (MELEIRO, 2002). Educar e cuidar estão, mais intensamente, vinculados neste nível de ensino, pois cabe à professora promover o ensino e a aprendizagem dos conhecimentos socialmente estabelecidos para a educação infantil, bem como tratar das expectativas e ansiedades das crianças frente ao novo universo de convívio social e de formação. Diante disso, compreende-se que a experiência de stress vivida na docência neste nível de ensino perpassa pela capacidade de lidar/mediar relações, valores, expectativas, ansiedades, tanto da criança, da família, dos pares e dos gestores educacionais, como também lidar com seus próprios anseios como docente, podendo repercutir em intensificação do trabalho docente e adoecimento. 
Tendo em vista a alta frequência de professoras diagnosticadas com sintomas de stress, sobretudo na fase de resistência, e considerando as fontes de stress apontadas no ambiente escolar é plausível inferir que muitos desses estressores que ocorrem na rotina de trabalho atuam por tempo considerável sobre seus corpos e mentes acarretando prejuízos à saúde física e mental. Enfatiza-se, neste esteio, a consequente insatisfação frente a essas circunstâncias desfavoráveis, bem como os constantes desafios advindos das mudanças ocorridas na função de professor que exigem lidar com questões que vão além das suas atividades pedagógicas.

Ressalta-se, ainda, a possibilidade de migração das professoras da fase de resistência para fases mais adiantadas do stress, como por exemplo a de quase-exaustão, caso não sejam desenvolvidas ações, em curto prazo, que possam facilitar que a docente recupere a sua homeostase interna e possa melhor administrar as demandas e pressões advindas da rotina de trabalho.

Em relação às sintomatologias físicas e psicológicas podem-se compreender as suas repercussões na motivação, produtividade, capacidade e qualidade de trabalho do professor, bem como na sua qualidade de vida.

Dessa maneira, é pertinente considerar a multiplicidade e a interrelação dos fatores pessoais, profissionais, sociais, culturais, ambientais, dentre outros, para compreender a professora da educação infantil e pensar em programas de enfrentamento e, em especial, de prevenção do stress ocupacional. Nesse esteio, considerando que o ato de ser professor perpassa pela mediação de conhecimentos específicos da docência, mas também afeta e é afetado pelas atitudes, emoções e condições de saúde dos docentes, desponta como uma das estratégias (evidentemente não a única necessária) para minorar o quadro de stress a que estão sujeitos os profissionais da educação, o desenvolvimento de ações no contexto da formação continuada que vise tanto o desenvolvimento pessoal quanto o desenvolvimento profissional dos professores.

Embora este estudo englobe uma população específica, ou seja, três grupos de professoras de uma rede municipal de educação do interior de São Paulo, seus indicadores podem ser considerados como indicios ou pistas para 
novas investigações com mais participantes e que envolvam outros segmentos da educação infantil, como por exemplo coordenadores-gestores. Acredita-se na relevância do estudo na medida em que deu mais um passo no sentido de sustentar um olhar mais atento e preciso para as professoras da educação infantil, contribuindo para a reflexão dessas não como seres abstratos, mas sim como seres sociais e com suas identidades pessoais e profissionais.

\section{Referências}

ANDRADE, P.S., CARDOSO, T.A. O prazer e a dor na docência: revisão bibliográfica sobre a Síndrome de Burnout. Saúde e Sociedade. v. 21, n. 1, p. 129-140, 2012.

ASSUNÇÃO, A. A.; OLIVEIRA, D. A. Intensificação do trabalho e saúde dos professores.

Educ. Soc., Campinas, v. 30, n. 107, p. 349-372, maio/ago. 2009.

BAUK, D.A. Stress. Rev Bras Saúde Ocup., v. 13, n. 50, p. 28-36, abr./jun. 1985.

BOA MORTE, S.V.R.; DEPS, V.L. Prevenção e tratamento do estresse e da sindrome de burnout em professores da rede pública de ensino. Revista Científica Interdisciplinar, v. 2, n. 1, p. 62-75, 2015.

BRASIL. MEC. INEP. Censo escolar 2017. Notas estatísticas. Brasília, DF. jan. 2018. p. 16. Disponivel em:

http://download.inep.gov.br/educacao_basica/censo_escolar/notas_estatisti cas/2018/notas_estatisticas_Censo_Escolar_2017.pdf.

CHIzZOTTI, A. Pesquisa em ciências humanas e sociais. 3.ed. São Paulo: Cortez, 1998.

FRANÇA, A.C.L.; RODRIGUES, A.L. Stress e trabalho: uma abordagem psicossomática. São Paulo: Atlas, 2002.

GASPARINI, S. M.; BARRETO, S. M.; ASSUNÇÃO, A. Á. O professor, as condições de trabalho e os efeitos sobre sua saúde. Educação e Pesquisa, São Paulo, v. 31, n. 2, p. 189-199, maio/ago. 2005.

GATTI, B. A. Formação continuada de professores: a questão psicossocial. Cadernos de Pesquisa, n. 119, p. 191-204, jul. 2003.

GOMES, R.M.S., PEREIRA, A.M.S. Estratégias de coping em educadores de infância portugueses. Psicologia Escolar e Educacional, v. 12, n. 2, p. 319326, dez. 2008. 
GONZÁLES REY, F. La investigación cualitativa en las ciencias sociales. In: Gonzáles Rey, F. Epistemologia cualitativa y subjetividad. São Paulo: EDU, 1997. p. 161-244.

IMBERNÓN, F. Formação permanente do professorado: novas tendências. São Paulo: Cortez, 2009.

Qualidade do ensino e formação do professorado: uma mudança necessária. São Paulo: Cortez, 2016.

KELLY, A.; CAREY, S. ; McCARTHY, S. ; COYLE, C. Challenging behavior principals" experience of stress and percepction of the effects of challenging behavior on staff in special schools in Ireland. European Journal Special Need Education. v. 22, n. 2, p.161-181, 2007.

LAZARUS, R.S.; FOLKMAN, S. Stress, appraisal and coping. New York: Springer, 1984.

LIPP, M.E.N. Stress e suas implicações. Estudos de Psicologia, v. 1, n.3/4. p. 5-19, 1984.

- Apostila do Inventário de Sintomas de Stress para Adultos de Lipp (ISSL). In: _. Manual do Inventário de Sintomas de Stress para Adultos de Lipp. São Paulo: Casa do Psicólogo, 2000.

. Inventário de sintomas de stress para adultos de Lipp. São Paulo. Casa do Psicólogo, 2005.

MARTINS, M.G.T. Sintomas de stress em professores brasileiros. Revista Lusófona de Educação, v. 10, p. 109-128, 2007.

MELEIRO, A.M.A.S. O stress do professor. In: LIPP, M.E.N. O stress do professor. Campinas: Papiros, 2008, p. 11-28.

NEDER, M. Ciclo de Vida no Atendimento Psicológico Hospitalar. Revista de Psicologia Hospitalar, v. 13, n. 1, p. 2-3, 1997.

NÓVOA, A. Os professores na virada do milênio: do excesso dos discursos à pobreza das práticas. Revista Educação e Pesquisa. São Paulo, v. 25, n. 1, p. 11-20, jan.-jun. 1999.

- Os professores e as histórias da sua vida. In: . (Org.). Vidas de professores. Porto: Porto Editora, 2000. p. 11-30.

POCINHO, M.; CAPELO, M.R. Vulnerabilidade ao stress, estratégias de coping e autoeficácia em professores portugueses. Educação e Pesquisa, v. 35, n. 2, p. 351-367, 2009. 
REINHOLD, H. H. O sentido da vida: prevenção do stress e burnout em professores. (Tese de doutorado). Pontificia Universidade Católica de Campinas, Campinas, 2004.

ROSI, K.R.B.S. O stress do educador infantil: sintomas e fontes. Dissertação (Mestrado em Psicologia), Universidade Católica Dom Bosco, Campo Grande, MS: 2003.

ROSSI, F. Implicações da formação continuada na prática pedagógica do(a) professor(a) no âmbito da cultura corporal do movimento. (Tese de Doutorado em Ciências da Motricidade) - IB, UNESP Rio Claro, 2013.

Sentir, pensar e agir: a ioga na formação docente. In: XIV

SEMINÁRIO DE EDUCAÇÃO FÍSICA, São Paulo. Anais... XIV Seminário de Educação Física. Revista Brasileira de Educação Física e Esporte.

Suplemento n.11. São Paulo: USP, 2017. v. 31. p. 23, 2017.

SACRISTÁN, J. G. Consciência e acção sobre a prática como libertação profissional dos professores. In: NÓVOA, A. (Org.). Profissão professor. 2. ed. Porto: Porto Editora, 1999. p. 63-92.

SELYE, H. Stress: a tensão da vida. São Paulo: IBRASA, 1959.

SILVEIRA, K.A.; ENUMO, S.R.F.; PAULA, K. M. P. Estresse e enfrentamento em professores: uma análise de literatura. Educação em Revista, v. 30, n. 4, p.15-36, out./dez. 2014.

SOUZA, A. M N. A família é um sistema vivo. In: SOUZA, A. M. N. A família e seu espaço: uma proposta de terapia familiar. Rio de Janeiro: Agir, 1997. p. 61-81.

VASCONCELOS, E.G. A psiconeuroimunologia da AIDS. In: Paiva V.S.F. Em tempos de AIDS. São Paulo: Summus, 1992.

VIANNA, C.P. O sexo e o gênero da docência. Cadernos Pagu, n.17-18, p. 81$103,2001 / 2002$.

VIEIRA, L.F.; OLIVEIRA, T.G. As condições do trabalho docente na educação infantil no Brasil: alguns resultados de pesquisa (2002-2012). Revista Educação em Questão, v. 46, n. 32, p. 131-154, maio/ago. 2013.

ZIBETTI, M. L. T.; PEREIRA, S. R. Mulheres e professoras: repercussões da dupla jornada nas condições de vida e no trabalho docente. Educar em Revista, n. especial 2, Curitiba, Brasil, p. 259-276, 2010. 